\title{
Lightwand intubation is associated with less hemodynamic changes than fibreoptic intubation in normotensive, but not in hypertensive patients over the age of 60
}

\author{
[L'intubation avec stylet lumineux, comparé au fibroscope, entraîne moins de changements \\ hémodynamiques chez les patients normotendus, non chez les hypertendus, de plus de 60 ans]
}

Kohki Nishikawa MD, Mikito Kawamata MD PhD, Akiyoshi Namiki MD PhD

Purpose: To compare the effects of the lightwand and fibreoptic techniques for intubation, neither of which require laryngoscopy, on hemodynamic responses associated with tracheal intubation in normotensive and hypertensive elderly patients.

Methods: Eighty-eight normotensive and hypertensive patients aged more than $60 \mathrm{yr}$ were randomly allocated to either the lightwand (LN and LH group, $n=22$ in both) or the fibreoptic group (FN and FH group, $n=22$ in both). All intubations were performed after induction of anesthesia with fentanyl and propofol and muscle relaxation with vecuronium. Systolic and mean arterial pressures (SAP and MAP) and heart rate (HR) were recorded, and rate-pressure product (RPP) and the change from "before intubation" to "immediately after intubation" of each variable $\triangle M A P \Delta, H R$ and $\Delta$ RPP) were calculated.

Results: In normotensive patients, significantly smaller $\triangle M A P, \Delta H R$ and $\Delta$ RPP were observed in the $L N$ group than in the FN group $(P$ $<0.05)$. In hypertensive patients, no significant differences between the $\mathrm{LH}$ group and the $\mathrm{FH}$ group were found in $\triangle \mathrm{MAP}$ or $\Delta \mathrm{HR}$, while values of mean RPP in both groups were less than 20,000.

Conclusion: We conclude that the lightwand technique significantly attenuates hemodynamic changes following intubation in comparison with fibreoptic intubation in normotensive patients over the age of 60 . Hemodynamic changes following intubation using the lightwand technique and the fibreoptic technique in hypertensive elderly patients are similar. However, both techniques are useful for intubation in hypertensive elderly patients in terms of RPP.
Objectif: Comparer les effets de l'intubation avec stylet lumineux ou fibroscope, aucune ne nécessitant de laryngoscopie, sur les réactions hémodynamiques associées à l'intubation endotrachéale chez des patients âgés normotendus et hypertendus.

Méthode : Quatre-vingt-huit patients normotendus et hypertendus, de plus de 60 ans, ont été répartis au hasard en deux groupes d'intubation avec stylet lumineux (groupes $L N$ et $L H, n=22$ dans chacun) ou fibroscope (groupes $F N$ et $F H, n=22$ dans chacun). Les intubations ont été réalisées après l'induction de l'anesthésie avec du fentanyl et du propofol, et la curarisation avec du vécuronium. Les tensions artérielles systolique et moyenne (TAS et TAM) et la fréquence cardiaque $(F C)$ ont été enregistrées. De même le produit tensionfréquence (PTF) et les changements de chacune des variables ( $\triangle T$ TAM, $\triangle F C$ et $\triangle P T F)$ survenus depuis "avant l'intubation" jusqu'à "immédiatement après" ont été quantifiés.

Résultats : Chez les normotendus, on a observé des $\triangle T A M, \triangle F C$ et $\Delta$ PTF significativement plus faibles avec $L N$ qu'avec $F N(P<0,05)$. Chez les patients hypertendus, aucune différence significative de $\triangle T A M$ et de $\triangle F C$ n'a été notée entre les patients des groupes $L H$ et $F H$, alors que les valeurs du PTF moyen ont été de moins de 20000 dans les deux groupes.

Conclusion : L'usage du stylet lumineux, comparé au fibroscope, diminue donc de façon significative les changements hémodynamiques qui suivent l'intubation chez des patients normotendus de plus de 60 ans. Par contre, les deux techniques produisent des modifications hémodynamiques similaires chez les patients âgés hypertendus, mais demeurent utiles à l'intubation pour ces patients en termes de PTF.

From the Department of Anesthesiology, Sapporo Medical University, School of Medicine, Sapporo, Japan. Address correspondence to: Dr. Kohki Nishikawa, Department of Anesthesia, Otaru Hokusei Hospital, 8-18 Umegae-cho, Otaru,

Hokkaido 047-0044, Japan. Phone: +81-134-25-4321; Fax: +81-134-25-2888; E-mail: hokuseiope@mac.com Accepted for publication July 3, 2001.

Revision accepted August 29, 2001. 


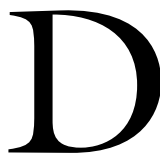

UE to the expanding elderly population in Japan in recent years, the number of patients over the age of 60 undergoing surgery under general anesthesia has been increasing. Elderly patients have a high incidence of coronary artery disease, and age is a major risk factor for perioperative cardiac morbidity. Transient hypertension and tachycardia associated with laryngoscopy and endotracheal intubation are probably of little consequence in young healthy patients, but either or both may be hazardous to elderly patients, ${ }^{1}$ especially to those with hypertension or myocardial insufficiency. ${ }^{2}$ Therefore, reduction of hemodynamic responses during tracheal intubation is of particular clinical importance in elderly patients with hypertension.

Attenuation of hemodynamic changes following tracheal intubation with a lightwand device has been attributed to the lack of stimulation by a laryngoscope. ${ }^{3-5}$ Fibreoptic endotracheal intubation, which requires neither elevation of the epiglottis nor exposure of the glottis by a laryngoscope blade, requires skill in manipulation of the endoscope. ${ }^{6}$ On the other hand, a lighted stylet also enables intubation to be performed without the use of laryngoscope. Additionally, this procedure is a simple and an easy-to-learn technique., ${ }^{7,8}$

The purpose of this study was to compare the effect of tracheal intubation with a lightwand device (Trachlight $^{\mathrm{TM}}$; TL - Laerdal Medical Inc., Wappingers Falls, New York, USA) and with a fibreoptic bronchoscope on changes in hemodynamics and the rate-pressure product (RPP) as an index of myocardial oxygen consumption in normotensive and hypertensive patients over the age of 60 .

Methods

After obtaining Institutional approval and informed consent from each patient, 88 normotensive and hypertensive patients ( $n=44$, respectively) aged more than 60 yr (ASA physical status I - II) scheduled for elective surgery under general anesthesia were included in this study. Uncooperative patients and patients with pulmonary diseases, cervical spine fracture, or tumours and polyps in the upper airway were excluded from the study. Hypertension was diagnosed if systolic blood pressure was $>160 \mathrm{mmHg}$ and/or diastolic blood pressure was $>95 \mathrm{mmHg}$ on admission (in accordance with the definition by the World Health Organization). Medically well-controlled hypertensive patients were classified as hypertensives, even if blood pressure was normal on admission. All patients in the hypertensive group were on calcium channel blockers and B-adrenergic blockers preoperatively, and they received their medication six hours before induction of anesthesia.
Normotensive and hypertensive patients were randomly assigned to one of two groups using a sealed envelope technique: (a) patients with hypertension intubated with the lightwand (LH group, $n=22$ ); (b) patients without hypertension intubated with the lightwand (LN group, $n=22$ ); (c) patients with hypertension intubated with the fibreoptic endoscope (FH group, $n=22$ ); (d) patients without hypertension intubated with the fibreoptic endoscope (FN group, $n=22$ ).

None of the patients received a premedication. Preanesthetic airway assessment was conducted using Mallampati et al's $s^{9}$ classification. Upon arrival in the operating room, lead II of the electrocardiogram was monitored, an 18-gauge $i v$ catheter was inserted in an upper extremity vein, and a blood pressure cuff was applied (BSM-8300; Nihonkohden, Sapporo, Japan). The patient's lungs were preoxygenated for three minutes, and anesthesia was induced with $2 \mu \mathrm{g} \cdot \mathrm{kg}^{-1}$ of fentanyl administered intravenously, followed by 1.5 $\mathrm{mg} \cdot \mathrm{kg}^{-1}$ propofol three minutes later. Vecuronium $\left(0.15 \mathrm{mg} \cdot \mathrm{kg}^{-1}\right)$ was given after loss of consciousness. The lungs were ventilated via face mask with $0.5 \%$ isoflurane and $66 \%$ nitrous oxide in oxygen, and manual ventilation was adjusted to maintain the end-tidal $\mathrm{CO}_{2}$ between 35 and $40 \mathrm{mmHg}$ using a Datex Capnomac (Helsinki, Finland), until the trachea was intubated orally.

In the LN and LH groups, the lightwand was introduced into the endotracheal tube and the proximal end of the tube was bent to a 90 angle. Room lights were dimmed, while the endotracheal tube was introduced into the oral cavity and advanced until midline illumination was observed in the anterior neck. Jaw lift was not applied. Then, the stylet was withdrawn, and the endotracheal tube was advanced until the glow disappeared behind the sternum. After the removal of the lightwand, the position of the endotracheal tube was confirmed by auscultation and capnography.

In the FN and FH groups, the endoscope (LF-2, Olympus, Optical, Tokyo, Japan) was passed through the endotracheal tube. With the jaw of the patient lifted by an assistant, the endoscope was advanced until the larynx was visualized and then passed through the vocal cords and trachea until the carina was visualized. Minimal force by which the oral cavity could be visualized through the endoscope was exerted to the patient's jaw by the assistant. After advancing the endotracheal tube, the endoscope was withdrawn, and appropriate placement of the endotracheal tube was confirmed by auscultation and capnography.

Three attempts at intubation were allowed for both techniques. Failure of intubation was defined as the inability to intubate after three attempts. An alternative 
TABLE I Demographic and baseline hemodynamic data

\begin{tabular}{|c|c|c|c|c|}
\hline & Normotensi & & Hyperten & \\
\hline & $F N$ & $L N$ & $F H$ & $L H$ \\
\hline$n$ & 22 & 22 & 22 & 21 \\
\hline $\operatorname{Gender}(\mathrm{m} / \mathrm{f})$ & $11 / 11$ & $11 / 11$ & $11 / 11$ & $10 / 11$ \\
\hline Age (yr) & $68.9 \pm 5.9$ & $73.0 \pm 5.8$ & $69.0 \pm 5.0$ & $71.9 \pm 8.1$ \\
\hline Height $(\mathrm{cm})$ & $158.7 \pm 8.9$ & $153.4 \pm 9.3$ & $157.1 \pm 9.6$ & $158.9 \pm 9.3$ \\
\hline Weight (kg) & $56.0 \pm 10.1$ & $50.6 \pm 11.2$ & $58.0 \pm 10.9$ & $58.1 \pm 10.2$ \\
\hline Baseline values & & & & \\
\hline $\mathrm{MAP}(\mathrm{mmHg})$ & $100.6 \pm 14.1$ & $98.8 \pm 11.3$ & $122.4 \pm 12.4^{*}$ & $119.4 \pm 13.7 \dagger$ \\
\hline HR (beats. $\min ^{-1}$ ) & $78.2 \pm 12.4$ & $70.1 \pm 10.9$ & $76.3 \pm 15.0$ & $72.5 \pm 9.5$ \\
\hline
\end{tabular}

All values are expressed as mean $\pm \mathrm{SD}$. MAP=mean arterial pressure; $\mathrm{HR}=$ heart rate. ${ }^{*} P<0.05$ compared with the FN group. $\dagger P<0.05$ compared with the LN group.

TABLE II Results and complications

\begin{tabular}{lllll}
\hline & \multicolumn{2}{c}{ Normotensive group } & \multicolumn{2}{c}{ Hypertensive group } \\
& $F N$ & $L N$ & FH & LH \\
\hline Duration of intubation (sec) & $59.9 \pm 39.7$ & $18.7 \pm 6.9^{* *}$ & $74.9 \pm 53.0$ & $40.8 \pm 32.5 \dagger$ \\
Number of intubation attempts & $1.4 \pm 0.6$ & $1.0 \pm 0.0^{*}$ & $1.3 \pm 0.7$ & $1.4 \pm 0.5$ \\
$\begin{array}{l}\text { Complications } \\
\quad \text { - Sore throat }\end{array}$ & 3 & 4 & 6 & 5 \\
$\quad$ - Hoarseness & 0 & 0 & 1 & 0 \\
\hline
\end{tabular}

All values are expressed as mean $\pm \mathrm{SD}$. ${ }^{*} P<0.05$ compared with the FN group; ${ }^{*} P<0.01$ compared with the FN group; $† P<0.05$ com pared with the FH group.

technique was introduced in cases of failure. The duration of each attempt and the time from the introduction of the device into the oral cavity until its removal were recorded. The duration of intubation was defined as the sum of the durations of all intubation attempts with each technique. The hemodynamic changes following tracheal intubation were evaluated after successful tracheal intubation.

For hypertension $(\mathrm{SAP}>200 \mathrm{mmHg}$, or an increase of $>30 \%$ above baseline values, for $>60 \mathrm{sec}$ ) or tachycardia $\left(\mathrm{HR}>130\right.$ beats $\cdot \mathrm{min}^{-1}$ for $>60 \mathrm{sec}$ ) associated with intubation, inspired isoflurane concentration was increased in increments of $0.5 \%$.

At the conclusion of surgery and anesthesia, all patients were asked whether they had a sore throat and hoarseness.

Data are presented as means \pm standard deviations (SDs). Statistical comparisons were performed by analysis of variance (ANOVA), followed by Student's $t$ test. A probability value $<0.05$ was considered statistically significant.

Results

All patients' airways were classified as Mallampati class I or II. No significant differences among the four groups were found in preoperative airway assessment.
One patient was excluded from the LH group due to failure after three attempts at intubation. The patient was intubated using conventional laryngoscopy.

There were no significant differences among the four groups in age, gender, height, and weight. (Table I). The duration of the intubation procedures was significantly shorter in the lightwand technique groups (LN and $\mathrm{LH}$ groups) than in the fibreoptic groups (FN and FH groups; $P<0.01$ ), while no difference between the number of attempts at intubation in the lightwand and fibreoptic groups was observed. The incidence of hoarseness and sore throat did not differ significantly among the four groups (Table II).

In normotensive patients (LN and FN groups), MAP significantly decreased from baseline following induction of anesthesia $(P<0.05)$. In the $\mathrm{FN}$ group, MAP showed a significant increase from baseline following intubation $(P<0.05)$, while there was no significant increase in the LN group. HR increased transiently after intubation in both the LN and FN groups. RPP in both groups also significantly increased from baseline after intubation $(P<0.05$; Figure 1). Significantly higher changes from "pre-intubation" to "immediately after intubation" in $\mathrm{MAP}, \mathrm{HR}$ and $\mathrm{RPP}(\triangle \mathrm{MAP}, \Delta \mathrm{HR}$ and $\triangle \mathrm{RPP})$ were observed in the FN group compared to the LN group ( $\triangle \mathrm{MAP}$ and $\triangle \mathrm{HR} ; P<0.01: \Delta \mathrm{RPP} ; P<0.05$; Figure 2 ). 

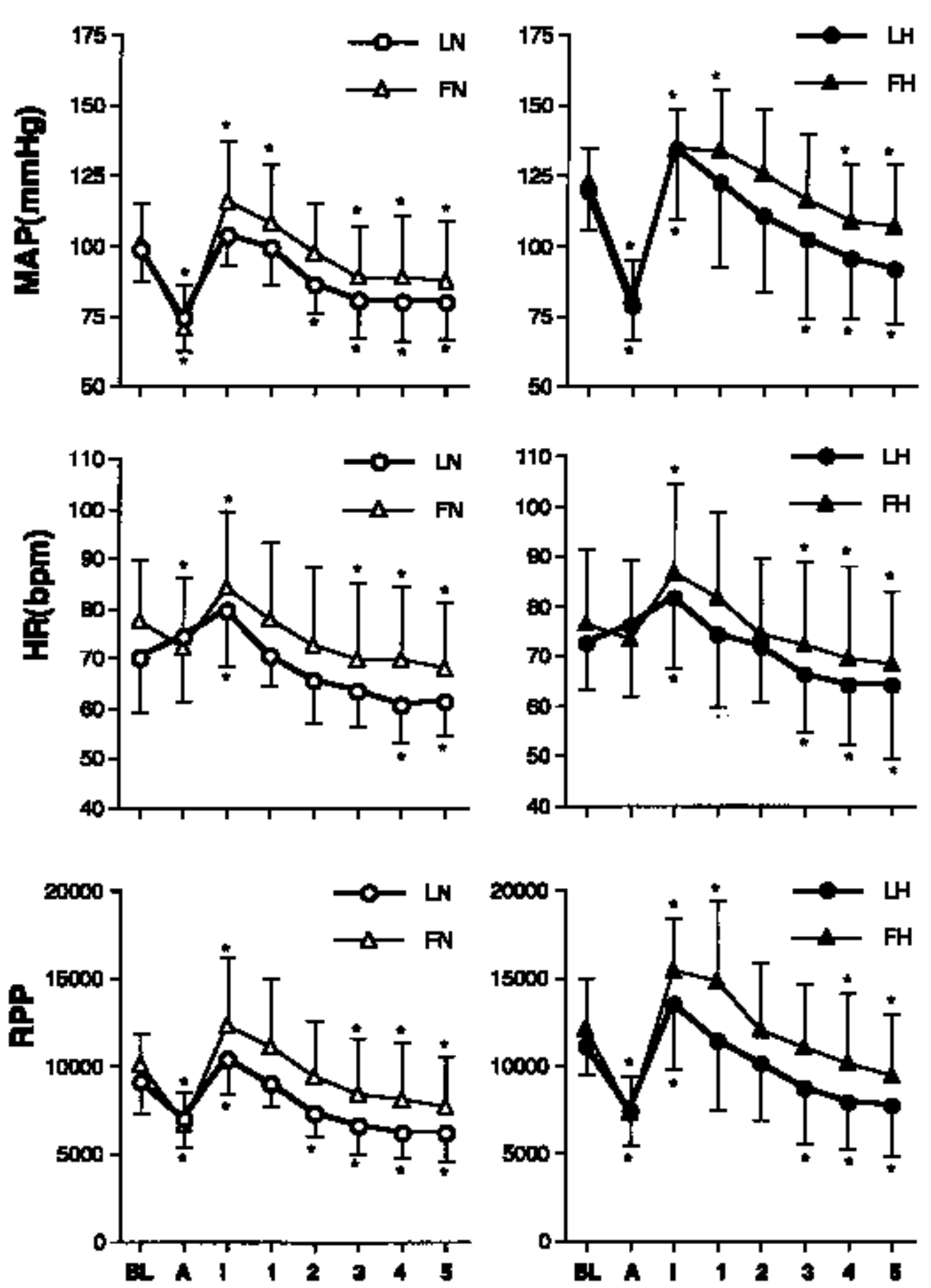

FIGURE 1 Hemodynamic changes following tracheal intubation in normotensive (LN $(\mathrm{O})$ and FN $(\Delta)$ groups) and hypertensive (LH $(\bullet)$ and $\mathrm{FH}(\quad)$ groups) patients. All values are expressed as mean $\pm \mathrm{SD}$. MAP=mean arterial pressure; $\mathrm{HR}=$ heart rate; $\mathrm{RPP}=$ rate-pressure product; $\mathrm{BL}=$ baseline; $\mathrm{A}=$ after induction of anesthesia; $\mathrm{I}=$ immediately after intubation; $1,2,3,4,5$, one, two, three, four, and five minutes after intubation, respectively; $\mathrm{LN}=$ patients without hypertension intubated with a lightwand; $\mathrm{LH}=$ patients with hypertension intubated with a lightwand; $\mathrm{FN}=$ patients without hypertension intubated with a fibreoptic endoscope; $\mathrm{FH}=$ patients with hypertension intubated with a fibreoptic endoscope. ${ }^{*} P<0.05$ compared with baseline values. 

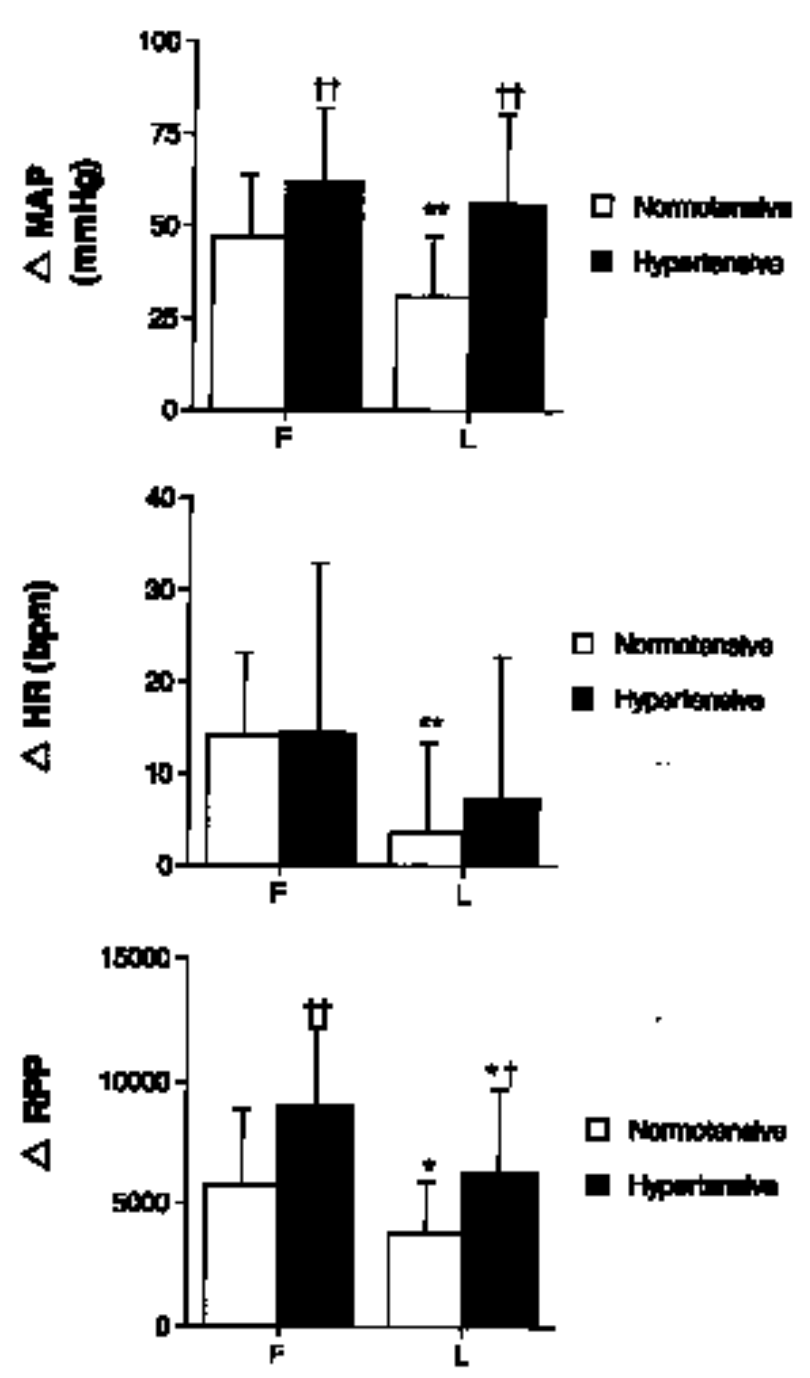

FIGURE 2 Comparison of changes from "before intubation" to "immediately after intubation" in MAP, HR and RPP ( $\triangle \mathrm{MAP}$, $\triangle \mathrm{HR}$, and $\triangle \mathrm{RPP}$ ) in normotensive and hypertensive patients. All values are expressed as mean $\pm \mathrm{SD}$. $\mathrm{MAP}=$ mean arterial pressure; $\mathrm{HR}=$ heart rate; $\mathrm{RPP}=$ rate- pressure product; $\mathrm{F}=$ patients without hypertension ( $\square$ ) and with hypertension ( $\square$ ) itubated with a fibreoptic endoscope; L=patients without hypertension ( $\square$ ) and with hypertension ( $)$ intubated with a lightwand. ${ }^{*} P<0.05$ vs FN or FH group, ${ }^{*} P<0.01$ vs $\mathrm{FN}$ group; $\dagger P<0.05$ vs normotensive group, $\dagger \dagger P<0.01$ vs normotensive group.

In hypertensive patients ( $\mathrm{LH}$ and $\mathrm{FH}$ groups), baseline values of MAP were higher than those in normotensive patients $(P<0.05$; Table I). MAP decreased following anesthesia induction and then increased from the baseline value following intubation in both groups $(P<0.05)$. The increase in MAP was sustained for over one minute after intubation in the $\mathrm{FH}$ group, while that in the LH group lasted less than one minute. HR transiently increased after intubation in both groups. A significant increase in RPP from baseline was maintained over one minute in the $\mathrm{FH}$ group but lasted less than one minute in the LH group $(P<0.05$; Figure 1$)$. There was no difference between the $\mathrm{LH}$ and $\mathrm{FH}$ groups in either MAP or HR. However, the increase in RPP associated with tracheal intubation $(\triangle R P P)$ was lesser in the LH group than in the FH group $(P<0.05)$. MAP was greater in the $\mathrm{LH}$ and $\mathrm{FH}$ groups than in the LN and FN groups $(P<0.01$; Figure 2$)$.

A SAP of $>200 \mathrm{mmHg}$ occurred in only one patient in the FH group. None of the patients in the other groups required treatment for hypertension following intubation. No ST segment changes associated with hypertension and/or tachycardia after intubation were observed in any of the patients.

\section{Discussion}

The results of our study indicate that tracheal intubation using the lightwand device was associated with less hemodynamic changes after intubation than was fibreoptic intubation in normotensive elderly patients, while hemodynamic changes after intubation using the lightwand technique and those after intubation using the fibreoptic technique did not differ significantly in hypertensive elderly patients. The increase in RPP after tracheal intubation using the lightwand technique was significantly less than that using the fibreoptic technique.

Due to the recently expanding elderly population in Japan, the number of elderly patients undergoing surgery under general anesthesia has been increasing. Elderly patients have a high incidence of clinical and occult coronary artery disease, and age is a major risk factor for perioperative cardiac morbidity. This risk may be minimized by maintenance of a balance between myocardial oxygen supply and demand. During the perioperative period, this balance is best preserved by avoidance of periods of significant hypotension, hypertension and tachycardia. ${ }^{1}$ Elderly patients also have a higher incidence of hypertension compared with young and middle-aged patients, and hypertensive patients are prone to greater circulatory responses after tracheal intubation than are normotensive patients. ${ }^{2}$ Thus, the maintenance of hemodynamic stability during tracheal intubation is of particular clinical importance in elderly patients with hypertension.

Prevention of hemodynamic changes following tracheal intubation due to the lack of stimulation by a laryngoscope has been reported. ${ }^{3-5}$ In the present study, we used lightwand-assisted and fibreoptic intu- 
bation as intubating techniques that do not require direct-vision laryngoscopy. Fibreoptic tracheal intubation in the conscious state has frequently been used as the gold standard for managing cases of predicted difficult intubation. However, fibreoptic procedures require a high level of skill in manipulation of the endoscope. Indeed, it has been reported that the most common cause of failure of fibreoptic intubation is a lack of experience under well-controlled conditions. ${ }^{6}$ On the other hand, the lightwand technique can be learned easily, ${ }^{7}$ and the overall success rate by anesthesia residents with little or no previous experience is more than $80 \%{ }^{8}$

In the current study, the lightwand technique caused a smaller increase in MAP and HR, and consequently in RPP, than did fibreoptic intubation in normotensive patients. Prolongation of the duration of intubation has been reported to increase hemodynamic changes after tracheal intubation. ${ }^{10}$ Saha et al. ${ }^{11}$ found the lightwand technique to be significantly faster than the fibreoptic technique for performing tracheal intubation in awake patients. It was also found in the present study that the intubation times in the lightwand groups were significantly shorter than those in the fibreoptic groups. Rapidity of intubation may have been one of the main reasons for the difference between MAP increases after intubation in the normotensive groups (TN and FN groups). In addition, Hirabayashi et al. ${ }^{12}$ reported that grasping the jaw and lifting it upward by using the thumb and index finger to make a clear passage for the tracheal tube in the lightwand technique produced the same hemodynamic changes as those due to laryngoscopyinduced stimulation. In the case of anesthetized and paralyzed patients, fibreoptic intubation requires maintenance of a potent airway during viewing of the vocal cords and passage of a tracheal tube. For this reason, we maintained the airway by having an assistant lift the jaw during endoscopy, while the lightwand technique did not require this procedure. These additional differences between the procedures used in the lightwand and fibreoptic groups may also have had an impact on hemodynamic changes after intubation.

In hypertensive patients, changes in MAP and HR following lightwand-assisted intubation were similar to those after fibreoptic intubation despite the fact that the time to intubation was shorter and manipulation by an assistant was not needed in the lightwandassisted intubation. Hypertensive patients have an exaggerated hemodynamic response to many forms of stress because of long-term persistent vascular hyperreactivity. ${ }^{13}$ In the lightwand technique, some degree of stimulus is applied to the upper airway because the procedure is performed without visualization of the laryngeal structure. Therefore, direct upper airway stimulation by the lightwand may have minimized two advantages of the technique, i.e., a short time to intubation and a lack of stimulation to the patient's jaw.

Values of RPP of more than 20,000 have been shown to be associated with angina and myocardial ischemia. ${ }^{14,15}$ However, the maximal value of mean RPP in the four groups in our study was $<16,000$, and there were no problems in safety with either the lightwand or fibreoptic techniques. The absence of direct laryngoscopy-induced stimulation in both groups may help explain the present results. Mean values of RPP after direct laryngoscopy and tracheal intubation in hypertensive patients in previous studies were near or $>20,000 .^{16,17}$

In conclusion, tracheal intubation using a lightwand is more effective than fibreoptic intubation in attenuating hemodynamic changes after tracheal intubation in normotensive elderly patients. In hypertensive elderly patients, the increase in MAP associated with tracheal intubation is larger than that in normotensive patients with the use of both devices, and the lightwand intubation-induced hemodynamic changes are similar to those using the fibreoptic endoscope. The RPP is maintained within acceptable limits with both devices under the conditions described.

\section{References}

1 Mangano DT. Perioperative cardiac morbidity. Anesthesiology 1990; 72: 153-84.

2 Prys-Roberts C, Greene LT, Meloche R, Fö̈x P. Studies of anaesthesia in relation to hypertension II: haemodynamic consequences of induction and endotracheal intubation. Br J Anaesth 1971; 43: 531-47.

3 Hung OR, Stewart RD. Lightwand intubation: I - a new lightwand device. Can J Anaesth 1995; 42: 820-5.

4 Hung OR, Pytka S, Morris I, Murphy M, Stewart RD. Lightwand intubation: II - clinical trial of a new lightwand for tracheal intubation in patients with difficult airways. Can J Anaesth 1995; 42: 826-30.

5 Nishikawa K, Omote K, Kawana S, Namiki A A comparison of hemodynamic changes after endotracheal intubation using the lightwand device and the laryngoscope in normotensive and hypertensive patients. Anesth Analg 2000; 90: 1203-7.

6 Ovassapian A Fiberoptic tracheal intubation in adults. In: Ovassapian A, (Ed.). Fiberoptic Endoscopy and the Difficult Airway. Philadelphia: Lippincott-Raven, 1996: 71-103.

7 Ellis DG, Jakymec A, Kaplan RM, et al. Guided orotracheal intubation in the operating room using a lighted 
stylet: a comparison with direct laryngoscopic technique. Anesthesiology 1986; 64: 823-6.

8 Fisher QA, Tunkel DE. Lightwand intubation of infants and children. J Clin Anesth 1997; 9: 275-9.

9 Mallampati SR, Gatt SP, Gugino LD, et al. A clinical sign to predict difficult tracheal intubation: a prospective study. Can Anaesth Soc J 1985; 32: 429-34.

10 Stoelting $R K$. Circulatory changes during direct laryngoscopy and tracheal intubation: influence of duration of laryngoscopy with or without prior lidocaine. Anesthesiology 1977; 47: 381-3.

11 Saba AK, Higgins M, Walker G, Badr A, Berman L. Comparison of awake endotracheal intubation in patients with cervical spine disease: the lighted intubating stylet versus the fiberoptic bronchoscope. Anesth Analg 1998; 87: 477-9.

12 Hirabayashi $\Upsilon$, Hiruta M, Kawakami T, et al. Effects of lightwand (Trachlight) compared with direct laryngoscopy on circulatory responses to tracheal intubation. Br J Anaesth 1998; 81: 253-5.

13 Goldman L, Caldera DL. Risks of general anesthesia and elective operation in the hypertensive patient. Anesthesiology 1979; 50: 285-92.

14 Robinson BF. Relation of heart rate and systolic blood pressure to the onset of pain in angina pectoris. Circulation 1967; 35: 1073-83.

15 Gobel FL, Nordstrom LA, Nelson RR, Jorgensen CR, Wang $\Upsilon$. The rate-pressure product as an index of myocardial oxygen consumption during exercise in patients with angina pectoris. Circulation 1978; 57: 549-56.

16 Omote K, Kirita A, Namiki A, Iwasaki H. Effects of nicardipine on the circulatory responses to tracheal intubation in normotensive and hypertensive patients. Anaesthesia 1992; 47: 24-7.

17 Fujii $\Upsilon$, Tanaka $H$, Saitoh $\Upsilon$, Toyooka $H$ Effects of calcium channel blockers on circulatory response to tracheal intubation in hypertensive patients: nicardipine versus diltiazem. Can J Anaesth 1995; 42: 785-8. 